\title{
Thermal and electro-optic properties of graphene oxide-doped hexylcyanobiphenyl liquid crystal
}

\author{
Şükrü Özgan ${ }^{1}\left[\right.$ D Hasan Eskalen ${ }^{2} \cdot$ Yusuf Tapkıranlı
}

Received: 7 September 2018 / Accepted: 21 October 2018 / Published online: 27 October 2018

(c) The Author(s) 2018

\begin{abstract}
Hexylcyanobiphenyl liquid crystal was doped with graphene oxide at ratios $\% 0.25 \mathrm{GO}, \% 0.5 \mathrm{GO}, \% 1 \mathrm{GO}$ and $\% 2 \mathrm{GO}$, and the change in physical properties of pristine and the doped liquid crystals has been investigated. The phase transitions of prepared samples were studied by differential scanning calorimeter and polarized optical microscopy. The differential scanning calorimeter and polarized optical microscopy results are in good agreement when examining the nematic-isotropic liquid phase transition temperatures of the hexylcyanobiphenyl. The liquid crystal texture images obtained with polarized optical microscopy reveals that thermal stability of sample changed with graphene oxide concentration, i.e., increased with graphene oxide concentration. Impedance, capacitance, conductivity and real and imaginary dielectric constants of the pure and doped liquid crystals were obtained depending on frequency and voltage at the room temperature by using impedance analyzer. These electrical properties of the pure and the graphene oxide-doped samples showed an increase with increasing the graphene oxide ratio. The voltage-dependent light transmittance experiment revealed that threshold voltage of LC cells decreased for $\% 0.25 \mathrm{GO}$ - and $\% 1 \mathrm{GO}$-dispersed samples, but it was increased at \%0.5GO- and \%2GO-dispersed samples.
\end{abstract}

Keywords Liquid crystal · Graphene oxide · Thermal and electro-optic properties $\cdot$ DSC $\cdot$ POM $\cdot$ Dielectric

\section{Introduction}

Nanoparticles (NPs) are materials having 1-100 nm size ranges. NPs can be classified into different classes depending on their sizes, shapes or properties. They have also been divided as metallic, ceramic and polymeric groups. NPs exhibit unique physical and chemical properties due to their large interaction surface area and nanoscale size. NPs can be used for catalysis, imaging, medical applications, energybased research and environmental applications [1].

Liquid crystals (LCs) which have intermediate physical properties between a solid and an isotropic liquid are very important materials. Due to these important features, LCs have a wide range of applications in technology. They are used for television, computer, machines display systems,

Şükrü Özgan

ozgans@gmail.com

1 Department of Physics, Kahramanmaraş Sütçü İmam University, 46100 Kahramanmaraş, Turkey

2 Materials Science and Engineering Program, Institute of Science and Technology, Kahramanmaraş Sütçü İmam University, 46100 Kahramanmaraş, Turkey electro-optic filters, lens [2, 3], holography [4-6], digital data storage [7] and biosensor. Different properties LCs' are needed for diverse applications areas. For these reasons, the required enhanced properties of liquid crystals are obtained by synthesizing a new liquid crystals $[8,9]$ and/or a mixture of two or more different liquid crystals [10-12] and/or using polymer [13-15], nanoparticles [16-19] and dyes [20, 21] and/or using at least two of them to reveal their LC behavior [22-24]. Among all of them, NPs are very important to obtain liquid crystals having different physical properties. When very small amount of NP is doped, the LCs' physical properties changed significantly [25]. NPs doped LCs research has attracted great interest in recent years. Electrooptical properties of various nanoparticles ranging from zinc oxide to gold were examined [17, 18, 25-27]. The threshold voltage has been studied by capacitance-voltage measurements of barium titanate $\left(\mathrm{BaTiO}_{3}\right) \mathrm{NP}$ doped pentylcyanobiphenyl (5CB) liquid crystal [28]. Effect of barium titanate nanoparticles of different particle sizes on electro-optic and dielectric properties of ferroelectric liquid crystal has been investigated [29]. Effects of ferroelectric nanoparticles on free ion concentration in a $5 \mathrm{CB}$ liquid crystal have been studied [30]. 
Carbon family materials as a LC dopant have attracted researcher's interest recently. Among the family members, carbon nanotubes have been investigated deeply. Twodimensional graphene and graphene oxide (GO) nanoparticles, on the other hand, have newly found a place in LC-related research. Graphene might be used in plasmonic logic gate to change dielectric constant [31]. It was found that phase transition temperature decreased with graphene dopant in nematic liquid crystals [32]. GO dispersed in the nematic liquid crystal (5CB) with different concentrations, and the dielectric and the electro-optic behavior was investigated [33]. The phase transitions and physiochemical properties of 5CB and heptylcyanobiphenyl (7CB) doped GO were studied [34]. Threshold voltage decreased with GO nanoparticles, and the same process is found for GO dispersed in polymer doped liquid crystals [35].

This work has been devoted to investigate the electrical, morphological, thermal and electro-optical properties of nematic liquid crystal $6 \mathrm{CB}$ by dispersing different rates of graphene oxide. We doped the $6 \mathrm{CB}$ liquid crystal with $\mathrm{GO}$ nanoparticle at ratios $\% 0.25 \mathrm{GO}, \% 0.5 \mathrm{GO}, \% 1 \mathrm{GO}$ and $\% 2 \mathrm{GO}$ ratio. The thermal, light transmittance, phase transitions and impedance, capacitance, conductivity and real and imaginary dielectric constants of the doped 6CB liquid crystal have been investigated.

\section{Experimental}

Hexylcyanobiphenyl 6CB liquid crystal used in this study is a nematic LC from cyanobiphenyl $\mathrm{nCB}$ group, purchased from Sigma-Aldrich company. The chemical structure of pure nematic mesogen 6CB is shown in Fig. 1. Dopant material graphene oxide is bought from GrafNano Inc Turkey. LC and GO solutions were dissolved in chloroform, and they were mixed together by three hours sonification. After evaporation of chloroform, $6 \mathrm{CB}$ and $\mathrm{GO}$ mixtures were obtained with certain ratios $\% 0.25 \mathrm{GO}, \% 0.5 \mathrm{GO}, \% 1 \mathrm{GO}$ and $\% 2 \mathrm{GO}$. To measure the electrical properties of GO-doped 6CB, samples were filled using capillarity method in indium tin oxide (ITO) cells. The planar alignment LC cells with cell gaps $8 \mu \mathrm{m}$ and $1 \mathrm{~cm}^{2}$ active area were purchased from Instec, Inc USA.

\section{Instruments and characterization}

The phase transition temperatures of $6 \mathrm{CB}+\mathrm{GO}$ mixtures were experimentally measured by a PerkinElmer differential scanning calorimeter (DSC). The samples were weighted as approximately $8 \mathrm{mg}$ and placed on an aluminum pan in DSC. The measurements were performed using continuous heating and cooling with $5^{\circ} \mathrm{C} / \mathrm{min}$ at temperature range between $-10^{\circ} \mathrm{C}$ and $60^{\circ} \mathrm{C}$ in pure argon medium.

To investigate the morphological texture of the $6 \mathrm{CB}+\mathrm{GO}$ samples was used Eclipse E200, Nikon Japan Polarized optical microscope (POM) equipped with the digital camera. Temperature of sample was controlled with heating stage LTS 120, with PE95 LinkPad accuracy of $\pm 0.1^{\circ} \mathrm{C}$ from Linkam Scientific Instrument, Ltd., England. POM studies were carried out not only to observe the morphological texture of prepared samples but also to monitor phase transitions.

Impedance, capacitance, conductivity and real and imaginary dielectric constants of the $6 \mathrm{CB}+\mathrm{GO}$ samples were obtained by HP 4194A impedance analyzer within the frequency range of $100 \mathrm{~Hz}-10 \mathrm{MHz}$ and depending on the direct current voltage at the room temperature. The light transmittance measurements of the $6 \mathrm{CB}+\mathrm{GO}$ samples were studied by an assembly consisting of $\mathrm{He}-\mathrm{Ne}$ laser, polarizer, analyzer, LC cell and photodetector as shown in Fig. 2. The light transmittance experiment of pure and doped LC samples was performed by observing laser light transmission intensity increasing from 0 to $6 \mathrm{~V}$ with 0.1 at the room temperature.
Fig. 1 Chemical structure of pure $6 \mathrm{CB}$ liquid crystal of light transmittance assembly

$\underline{\text { LC Linear Formula }} \quad$ Chemical Structure Molecular Weight (g)

$6 \mathrm{CB}$

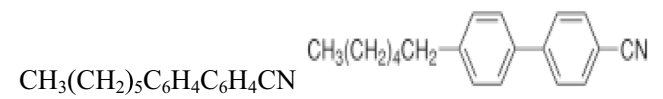

263.39

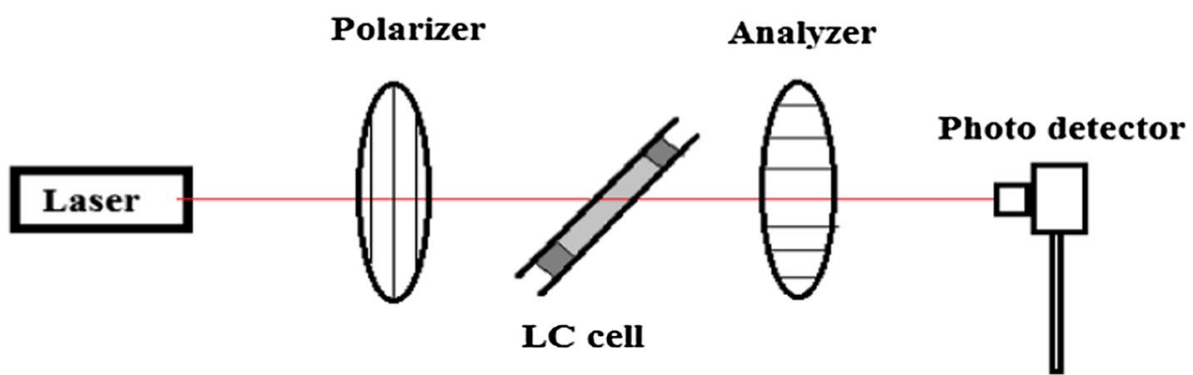




\section{Results and discussion}

\section{Thermal analysis}

The phase transition temperatures and thermal behavior of pure $6 \mathrm{CB}$ liquid crystal and its GO-doped samples were investigated using DSC with $5{ }^{\circ} \mathrm{C} / \mathrm{min}$ heating and cooling. DSC thermograms of $6 \mathrm{CB}+\% 0.5 \mathrm{GO}$ and $6 \mathrm{CB}+\% 1 \mathrm{GO}$ samples are shown in Fig. 3. The solidnematic and nematic-isotropic liquid transition temperature of $6 \mathrm{CB}+\% 0.5 \mathrm{GO}$ sample is $12.59^{\circ} \mathrm{C}$ and $24.37^{\circ} \mathrm{C}$ in heating process, respectively. The sample below the temperatures $12.59{ }^{\circ} \mathrm{C}$ was solid; between temperatures 12.59 and $24.37{ }^{\circ} \mathrm{C}$, the sample was in nematic phase; and above the temperature $24.37{ }^{\circ} \mathrm{C}$, the sample was in isotropic phase. For $6 \mathrm{CB}+\% 1 \mathrm{GO}$ sample, $12.36{ }^{\circ} \mathrm{C}$ and $23.22{ }^{\circ} \mathrm{C}$ are obtained as the solid-nematic and nematic-isotropic liquid transition temperatures.

The thermal behavior of 6CB and GO-doped LC samples using DSC with $5{ }^{\circ} \mathrm{C} / \mathrm{min}$ heating is shown in Fig. 4. All samples exhibit similar behavior depending on the increase in temperature. But there are some differences at phase transition temperatures of samples. Phase changes with respect to the transition temperature obtained and are given in Table 1. Tsn is solid-nematic, Tni is nematic-isotropic phase, and $\Delta T(\Delta T=\mathrm{Tni}-\mathrm{Tsn})$ is phase change with respect to temperature.

The nematic-isotropic liquid phase transition temperature of the pure $6 \mathrm{CB}$ was also verified by POM texture images at a certain temperature range as shown in Fig. 5. The phase transition starts at $24{ }^{\circ} \mathrm{C}$ and finishes at $27.6^{\circ} \mathrm{C}$. The phase transition texture images were taken with a

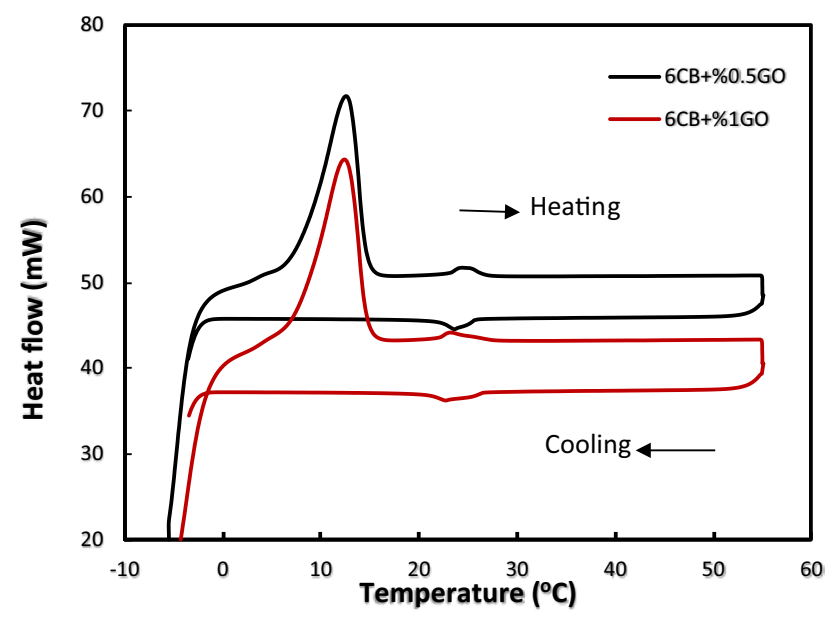

Fig. 3 DSC thermograms of $6 \mathrm{CB}+\% 0.5 \mathrm{GO}$ and $6 \mathrm{CB}+\% 1 \mathrm{GO}$ samples

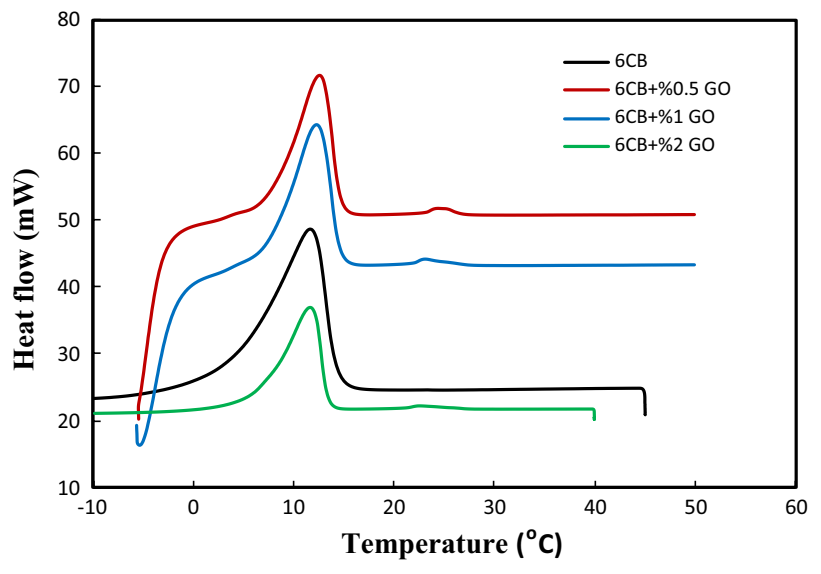

Fig. 4 DSC heating thermograms of 6CB and GO-doped LC samples

small temperature step. Material at $27.6{ }^{\circ} \mathrm{C}$ passed to isotropic phase completely.

\section{Electrical analysis}

It is very important to determine the electrical properties of LC materials when used in image processing systems. LC materials have positive or negative electrical and optical anisotropy since an external effect as an electric or magnetic field may change the orientation of liquid crystal molecules. So the dependency of the real and imaginary dielectric constants of the $6 \mathrm{CB}+\mathrm{GO}$ samples on the frequency and the voltage is investigated. Voltage-dependent change in inductance, capacitance and conductivity of the $6 \mathrm{CB}+\mathrm{GO}$ samples is studied.

Dielectric spectroscopy technique is used to determine the electrical properties of the materials. The dielectric complex expression can be written as

$\varepsilon^{*}=\varepsilon^{\prime}+i \varepsilon^{\prime \prime}$

where $\varepsilon^{\prime}$ and $\varepsilon^{\prime \prime}$ are the real and imaginary parts of the dielectric constant, respectively. The real part of the dielectric constant can be expressed as

$C=\varepsilon_{o} \varepsilon^{\prime} \frac{A}{d}$

Table 1 Phase transition temperatures of the pure and GO-doped samples

\begin{tabular}{llll}
\hline Material & Tsn & Tni & $\Delta T$ \\
\hline $6 \mathrm{CB}$ & 11.66 & 24.68 & 13.02 \\
$6 \mathrm{CB}+\% 0.5 \mathrm{GO}$ & 12.59 & 24.37 & 11.78 \\
$6 \mathrm{CB}+\% 1 \mathrm{GO}$ & 12.36 & 23.22 & 10.86 \\
$6 \mathrm{CB}+\% 2 \mathrm{GO}$ & 11.62 & 22.64 & 11.02 \\
\hline
\end{tabular}




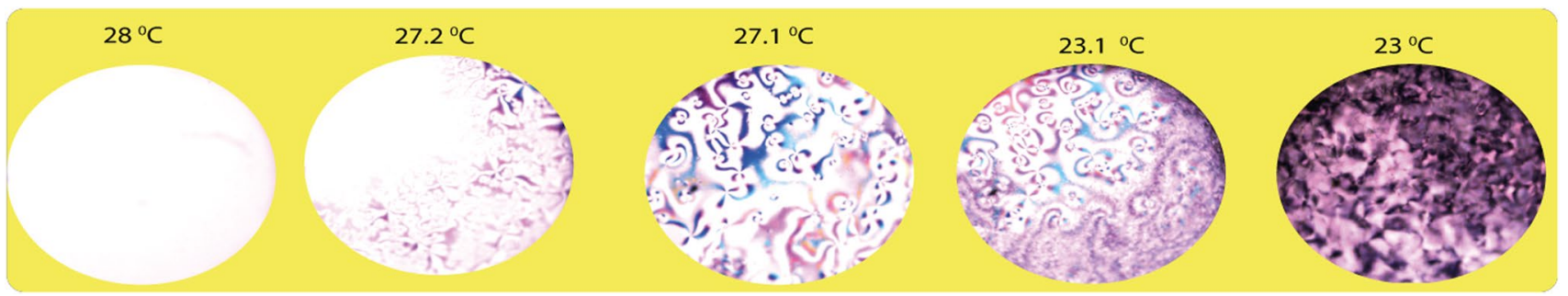

Fig. 5 Textural images of 6CB nematic-isotropic phase transition

where $C$ is capacitance, $\varepsilon_{o}$ is the permittivity constant of the free space, $A$ is the surface area of the cell and $d$ is the thickness of the cell. The imaginary part of the dielectric constant is known as the dielectric loss and calculated by this equation

$\varepsilon^{\prime \prime}=\varepsilon^{\prime} \tan \delta$

where $\delta=90-\phi$ and $\phi$ is the phase angle.

The Cole-Cole equality depending on the real and imaginary parts of the dielectric constant is given as

$\varepsilon^{*}=\varepsilon_{\infty}+\frac{\left(\varepsilon_{s}-\varepsilon_{\infty}\right)}{1+(i \omega \tau)^{1-\alpha}}$

where $\varepsilon_{s}$ is the value of the low-frequency dielectric constant, and $\varepsilon_{\infty}$ is the value of the high-frequency dielectric constant in the measured frequency range, $\omega$ is the angular frequency, $\tau$ is the relaxation time and $\alpha$ is the absorption coefficient.

The dielectric strength is the difference between the dielectric constant values at minimum and at maximum frequencies. The dielectric strength is expressed as

$\Delta \varepsilon=\varepsilon_{s}-\varepsilon_{\infty}$

The variation of the real dielectric constant of the $6 \mathrm{CB}+\mathrm{GO}$ samples depends on frequency and voltage as shown in Fig. 6a, b, respectively. Figure 6a is obtained between $1 \mathrm{kHz}$ and $10 \mathrm{MHz}$ frequency range at room temperature and zero voltage. This figure shows the real dielectric constant $\varepsilon^{\prime}$ versus the logarithm of applied frequency. The variation of the real dielectric constants between $100 \mathrm{~Hz}$ and $1 \mathrm{kHz}$ frequency range is very big, and it is not seen in this figure. So many studies have been done starting from $1 \mathrm{kHz}$ frequency [36]. Between 1 and $100 \mathrm{kHz}$ frequency range, $\varepsilon^{\prime}$ decreases and it goes to zero at high frequencies $(10 \mathrm{MHz})$.

Figure $6 \mathrm{~b}$ shows the real dielectric constant versus voltage curves at $1 \mathrm{kHz}$ frequency and at room temperature. The real dielectric constant value is high at low voltages, and the dielectric constant increases with the increase in the graphene oxide ratio.

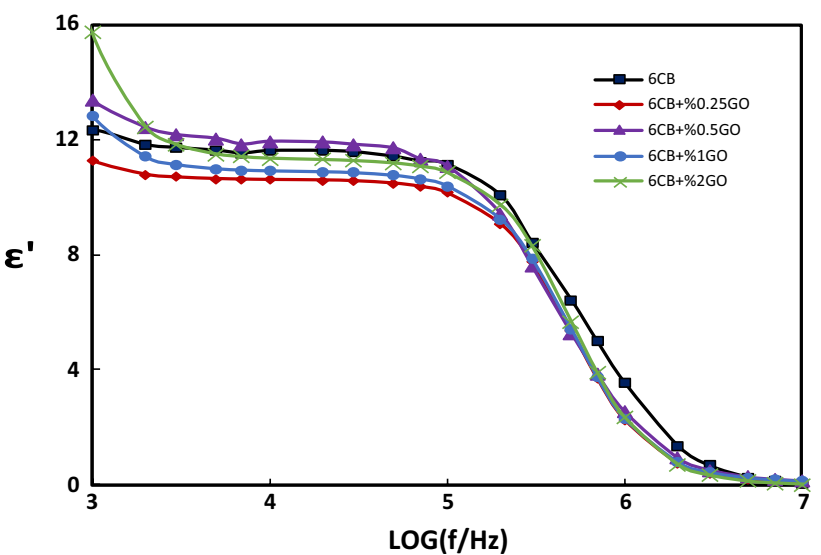

(a)



(b)

Fig. 6 Dependency of the real dielectric constant on a the frequency, b the voltage

The variation of the imaginary dielectric constant of the $6 \mathrm{CB}+\mathrm{GO}$ samples depends on frequency and voltage as shown in Fig. 7a, b, respectively. The imaginary dielectric is obtained between $1 \mathrm{kHz}$ and $10 \mathrm{MHz}$ frequency range at room temperature and zero DC voltage. $\varepsilon^{\prime \prime}$ has very large value at low voltages, and it reach a maximum value at $0.5 \mathrm{MHz}$ critical frequency. The dependency of the $\varepsilon^{\prime \prime}$ of the $6 \mathrm{CB}+\mathrm{GO}$ samples on voltage is given at $1 \mathrm{kHz}$ frequency and at room temperature as shown in Fig. $7 \mathrm{~b}$. The $\varepsilon^{\prime \prime}$ value 


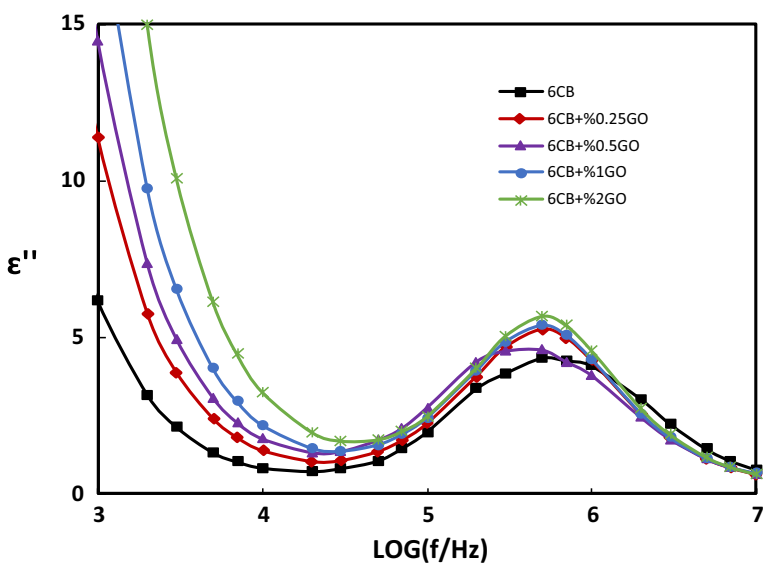

(a)



(b)

Fig. 7 Dependency of the imaginary dielectric constant on a the frequency, $\mathbf{b}$ the voltage



Fig. 8 Dependency of the real and imaginary dielectric constants on the frequency is high at low voltages, and it increases with the increase in the graphene oxide contribution ratio. The change in the real and imaginary dielectric constants of the 6CB and $6 \mathrm{CB}+\% 0.5 \mathrm{GO}$ samples depends on frequency and is shown in Fig. 8. The dielectric parts of the samples are $\varepsilon^{\prime}>\varepsilon^{\prime \prime}$ up to a certain frequency, about $1 \mathrm{MHz}$, and then, they are vice versa so $\varepsilon^{\prime}<\varepsilon^{\prime \prime}$. The difference of real and imaginary parts of dielectric constant below the critical frequency have higher values than the values at frequencies above the critical frequency.

The dielectric constant $\varepsilon_{s}$ minimum and $\varepsilon_{\infty}$ maximum values from Fig. 6a and the dielectric strength which is calculated using Eq. (5) are given in Table 2. The $\varepsilon_{s}$ is calculated at $100 \mathrm{kHz}$ and $1 \mathrm{kHz}$ frequencies. Dielectric anisotropy $\Delta \varepsilon$ of the pure $6 \mathrm{CB}$ is obtained as 28.37 for $100 \mathrm{kHz}$ minimum frequency, but it is 12.27 for $1 \mathrm{kHz}$ minimum frequency. Dielectric anisotropy of the $6 \mathrm{CB}+\% 2 \mathrm{GO}$ doped sample is seen as 148.63 for $100 \mathrm{kHz}$ and 15.70 for $1 \mathrm{kHz}$ minimum frequencies.

The fitted Cole-Cole plot of the pure and GO-doped samples is shown in Fig. 9. From this graph, one can get information about the $\varepsilon^{\prime}$ and $\varepsilon^{\prime \prime}$ dielectric constants at minimum and maximum frequencies. The maximum point of the semicircles is $\varepsilon_{\max }$, and its value can also be obtained from these plots for the $6 \mathrm{CB}+\mathrm{GO}$ samples.

Variation of absolute capacitance with voltage of the $6 \mathrm{CB}+\mathrm{GO}$ samples at $1 \mathrm{kHz}$ frequency is shown in Fig. 10 . The absolute capacitance has high values at low voltages, and the capacitance increases as the percentage of doped GO material increases. The capacitance of $6 \mathrm{CB}$ pure liquid is lower than GO-doped samples. Voltage dependence of absolute impedance of the $6 \mathrm{CB}+\mathrm{GO}$ samples at $1 \mathrm{kHz}$ frequency is shown in Fig. 11. The impedance of 6CB pure liquid crystal is higher than GO-doped samples. As the percentage of additive GO increases, the impedance decreases. Figure 12 shows the absolute conductivity depends on the voltage. The absolute conductivity has higher values at low voltages. With increasing GO percentage, the conductivity has higher values. So $6 \mathrm{CB}+\% 2 \mathrm{GO}$ sample has the highest conductivity from $6 \mathrm{CB}$ pure and $6 \mathrm{CB}+\mathrm{GO}$ samples.

\section{Optical analysis}

The light transmittance of the different ratios graphene oxide-doped 6CB liquid crystal samples measured by an assembly consisting of $\mathrm{He}-\mathrm{Ne}$ laser, polarizer, analyzer, LC cell and photodetector is shown in Fig. 2. The light transmittance measurment of ITO cells filled with pure and $6 \mathrm{CB}+\mathrm{GO}$ mixed samples was made by applying the different $\mathrm{AC}$ voltages at the room temperature. $\mathrm{AC}$ voltage was applied to conducting surfaces of the sample filled in ITO cell from $0 \mathrm{~V}$ to 6 volts with $0.1-\mathrm{V}$ increments. The 
Table 2 Dielectric anisotropy of the pure and GO-doped samples

\begin{tabular}{lclrlll}
\hline Material & $\varepsilon_{s}(f=100 \mathrm{~Hz})$ & $\varepsilon_{\infty}(f=10 \mathrm{MHz})$ & \multicolumn{1}{c}{$\Delta \varepsilon$} & $\varepsilon_{s}(f=1 \mathrm{kHz})$ & $\varepsilon_{\infty}(f=10 \mathrm{MHz})$ & $\Delta \varepsilon$ \\
\hline $6 \mathrm{CB}$ & 28.441300 & 0.069978 & 28.37 & 12.337350 & 0.069978 & 12.27 \\
6CB $+\% 0.25 \mathrm{GO}$ & 57.484300 & 0.102826 & 57.38 & 11.287200 & 0.102826 & 11.18 \\
$6 \mathrm{CB}+\% 0.5 \mathrm{GO}$ & 77.071900 & 0.152694 & 76.92 & 13.387500 & 0.152694 & 13.23 \\
$6 \mathrm{CB}+\% 1 \mathrm{GO}$ & 105.073000 & 0.136405 & 104.94 & 12.848100 & 0.136405 & 12.71 \\
$6 \mathrm{CB}+\% 2 \mathrm{GO}$ & 148.662000 & 0.031660 & 148.63 & 15.727600 & 0.031660 & 15.70 \\
\hline
\end{tabular}

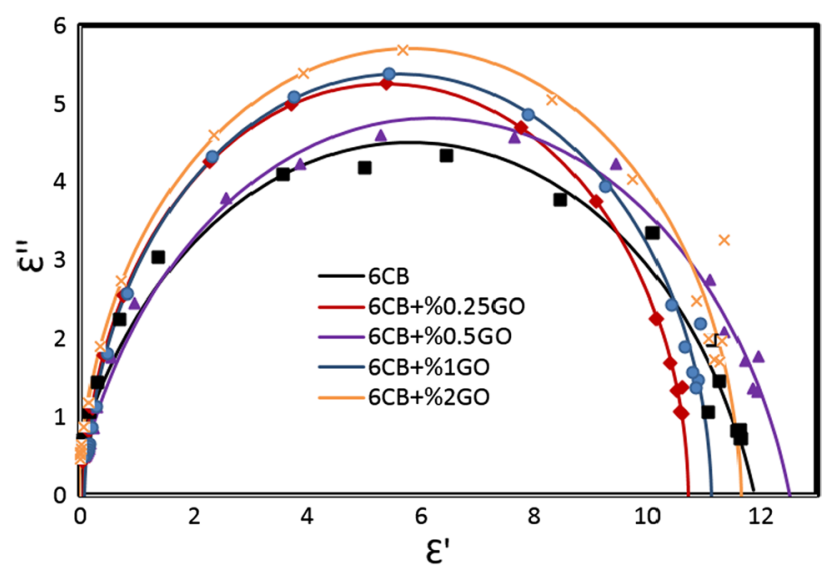

Fig. 9 Cole-Cole plots of the pure and GO-doped samples



Fig. 10 Variation of absolute capacitance with voltage

light transmittance value was recorded with photodetector for each volt step. The laser light wavelength used in experimental setup was $650 \mathrm{~nm}$. The required operating voltage of LC-GO system can be found by voltage-dependent light transmittance data. Figure 13 shows transmission voltage curves of pristine and $\% 0.25 \mathrm{GO}, \% 0.5 \mathrm{GO}, \% 1 \mathrm{GO}$ and $\% 2 \mathrm{GO}$ nanoparticles-doped LC cells. The threshold voltage of LC cells decreased for $\% 0.25 \mathrm{GO}$, but increased at $\% 0.5 \mathrm{GO}$ nanoparticles. The threshold voltage also

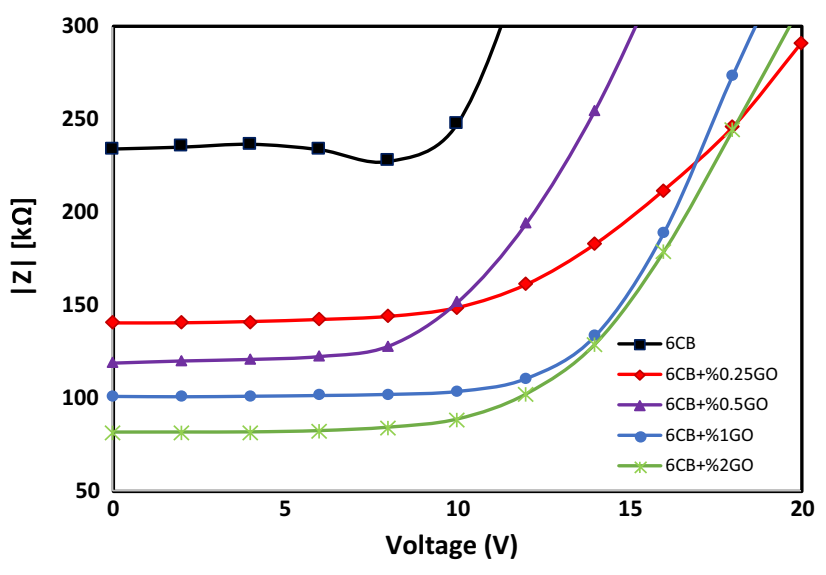

Fig. 11 Variation of absolute impedance with voltage

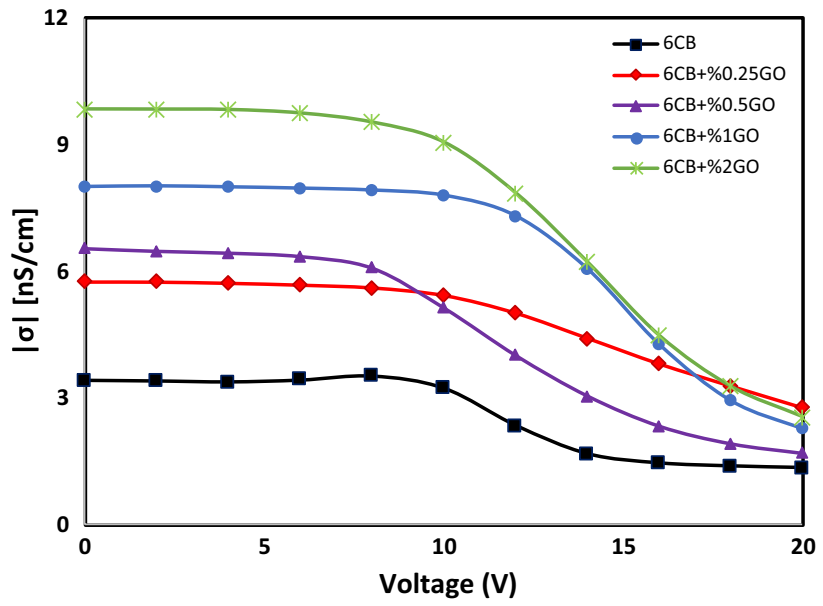

Fig. 12 Variation of absolute conductivity with voltage

decreased at $\% 1 \mathrm{GO}$ and increased at $\% 2 \mathrm{GO}$ dispersion compared to pure $6 \mathrm{CB}$.

\section{Conclusions}

In this study, hexylcyanobiphenyl liquid crystal was doped with graphene oxide at percentages of $\% 0.25 \mathrm{GO}, \% 0.5 \mathrm{GO}, \% 1 \mathrm{GO}$ and $\% 2 \mathrm{GO}$. From thermal 


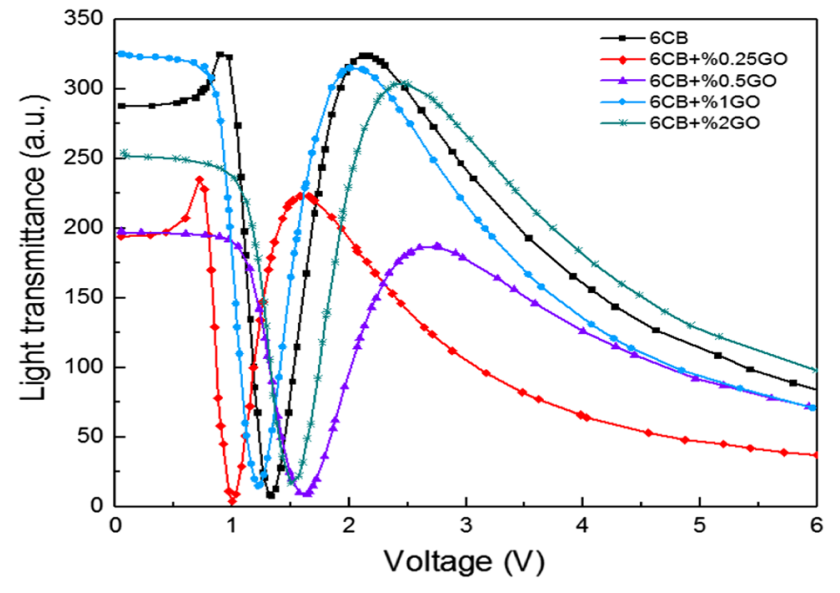

Fig. 13 Voltage-dependent light transmittance of the pure and GOdoped samples

behavior, it was found that increasing $\mathrm{GO}$ ratio in $6 \mathrm{CB}$ results in the reduction at the phase transition temperature. The real dielectric constant increases with increasing GO ratio in 6CB. Dielectric anisotropy of the 6CB pure and GO-dispersed samples was also increased with increasing concentration of GO nanoparticles. From the light transmission experiment, it was found that the threshold voltage of $\% 0.25 \mathrm{GO}$ - and $\% 1 \mathrm{GO}$-dispersed samples was decreased and \%0.5GO- and \%2GO-dispersed samples was increased. We assumed that this situation may be caused by non-homogeneous graphene oxide distribution in LC cells. Further studies will be needed to evaluate GO dispersibility and their stability in LC.

Acknowledgements The authors thank Kahramanmaraş Sütçü İmam University Scientific Research Projects Coordination Department for financially supported under Project No. 2017/1-47 YLS.

Open Access This article is distributed under the terms of the Creative Commons Attribution 4.0 International License (http://creativeco mmons.org/licenses/by/4.0/), which permits unrestricted use, distribution, and reproduction in any medium, provided you give appropriate credit to the original author(s) and the source, provide a link to the Creative Commons license, and indicate if changes were made.

\section{References}

1. Rihn, B.H.: Biomedical Application of Nanoparticles. CRC Press, Boca Raton (2017)

2. Lee, W., Gau, J.-S., Chen, H.-Y.: Electro-optical properties of planar nematic cells impregnated with carbon nanosolids. Appl. Phys. B 81, 171 (2005)

3. Areed, N.F., El-Baz, M., Heikal, A., Obayya, S.S.: Intensity modulation lens on the basis of nano-scale golden rods and liquid crystal layer. Opt. Quantum Electron. 50, 240 (2018)

4. Eich, M., Wendorff, J.H.: Erasable holograms in polymeric liquid crystals. Die Makromol. Chem. Rapid Commun. 8, 467 (1987)
5. Chen, A.G., Brady, D.J.: Real-time holography in azo-dye-doped liquid crystals. Opt. Lett. 17, 441 (1992)

6. Gupta, D.K., Tata, B., Ravindran, T. In. AIP Conference Proceedings AIP Publishing, p. 060028 (2017)

7. Matharu, A.S., Jeeva, S., Ramanujam, P.: Liquid crystals for holographic optical data storage. Chem. Soc. Rev. 36, 1868 (2007)

8. Gupta, M., Gupta, S.P., Mohapatra, S.S., Dhara, S., Pal, S.K.: Room-temperature oligomeric discotic nematic liquid crystals over a wide temperature range: structure-property relationships. Chem. Eur. J. 23, 10626 (2017)

9. Srinivasa, H., Kumar, S.: Synthesis and characterisation of some new chalcone liquid crystals. Liq. Cryst. 44, 1506 (2017)

10. Kumar, T.R., Sundaram, S., Chitravel, T., Jayaprakasam, R., Vijayakumar, V.N.: Design, synthesis and characterization of hydrogen bonded binary liquid crystal complex from 4-methoxycinnamic acid and 4-hexyloxybenzoic acid (4MCA:6OBA). Z. Phys. Chem. 231, 1875 (2017)

11. Sundaram, S., Subhasri, P., Vasanthi, T., Senthil, T., Jayaprakasam, R., Vijayakumar, V.: Experimental investigation on the effect of mesogenic ratio in hydrogen-bonded liquid crystal complexes. J. Dispers. Sci. Technol. 38, 1811 (2017)

12. Okumuş, M., Özgan, Ş.: Thermal and mesomorphic properties of ternary mixtures of some hydrogen-bonded liquid crystals. Liq. Cryst. 41, 1293 (2014)

13. Kumar, P., Sharma, V., Jaggi, C., Raina, K.K.: Dye-dependent studies on droplet pattern and electro-optic behaviour of polymer dispersed liquid crystal. Liq. Cryst. 44, 757 (2017)

14. Yang, D.-K.: Fundamentals of liquid crystal devices. Wiley, New York (2014)

15. Öztürk, E., Ocak, H., Cakar, F., Karanlık, G., Cankurtaran, Ö., Bilgin-Eran, B.: Investigation of thermodynamic properties of 4-decyloxybiphenyl-4'-carboxylic acid liquid crystal and preparation of polymer dispersed liquid crystal composite. J. Mol. Liq. 265, 24 (2018)

16. Eskalen, H., Kerli, S., Özgan, Ş.: Hydrothermally produced cobalt oxide nanostructures at different temperatures and effect on phase transition temperature and threshold voltage of nematic liquid crystal host. In: Maaz, K. (ed.) Cobalt, InTech, pp. 71-85 (2017)

17. Eskalen, H., Öz̆̆an, Ş.: Altın nanoparçaciklarla katkilandirilan nematik sivi kristallerin incelenmesi. Duzce Univ Bilim Teknol Derg 2, 407 (2014)

18. Sharma, A., Kumar, P., Malik, P. In: AIP Conference Proceedings AIP Publishing, p. 100037 (2018)

19. Pal, K., Mohan, M.M., Foley, M., Ahmed, W.: Emerging assembly of $\mathrm{ZnO}$-nanowires/graphene dispersed liquid crystal for switchable device modulation. Org. Electron. 56, 291 (2018)

20. Gürlük, M., Abdulkadir, H.A., Akkuş, M.S., Akkurt, F., Alicilar, A.: Comparison of guest-host liquid crystal systems doped with azo or anthraquinone dyes. Iran. J. Sci. Technol. Trans. A Sci. 41, 1 (2017)

21. Zakerhamidi, M., Kiani, S., Tajalli, H., Khoshsima, H.: Role of specific and nonspecific intermolecular interaction in electrooptical response of doped 6CHBT nematic liquid crystal with azo dyes. J. Mol. Liq. 221, 608 (2016)

22. Akkurt, F.: Characterisation of azo dye and carbon nanoparticledoped guest-host liquid crystalline matrix. Liq. Cryst. 41, 1269 (2014)

23. Kumar, P., Sharma, V., Jaggi, C., Malik, P., Raina, K.K.: Orientational control of liquid crystal molecules via carbon nanotubes and dichroic dye in polymer dispersed liquid crystal. Liq. Cryst. 44, 843 (2017)

24. Jayoti, D., Malik, P., Singh, A.: Analysis of morphological behaviour and electro-optical properties of silica nanoparticles doped polymer dispersed liquid crystal composites. J. Mol. Liq. 225, 456 (2017) 
25. Eskalen, H., Özğan, Ş., Alver, Ü., Kerli, S.: Electro-optical properties of liquid crystals composite with zinc oxide nanoparticles. Acta Phys. Pol. A 127, 756 (2015)

26. Sharma, V., Kumar, P.: Studies of absorption coefficient cum electro-optic performance of polymer dispersed liquid crystal doped with CNT and dichroic dye. Phys. B 524, 118 (2017)

27. Mun, H.-Y., Park, H.-G., Jeong, H.-C., Lee, J.H., Oh, B.-Y., Seo, D.-S.: Thermal and electro-optical properties of cerium-oxidedoped liquid-crystal devices. Liq. Cryst. 44, 538 (2017)

28. Humbatov, S., Ramazanov, M., İmamaliyev, A.: The study of $\mathrm{BaTiO}_{3}$ nanoparticles effect on threshold properties of Liquid Crystal 5CB. Mol. Cryst. Liq. Cryst. 646, 263 (2017)

29. Kumar, P., Sinha, A.: Effect of barium titanate nanoparticles of different particle sizes on electro-optic and dielectric properties of ferroelectric liquid crystal. Phase Transit 88, 605 (2015)

30. Basu, R., Garvey, A.: Effects of ferroelectric nanoparticles on ion transport in a liquid crystal. Appl. Phys. Lett. 105, 151905 (2014)

31. Vlădescu, E., Dragoman, D.: Reconfigurable plasmonic logic gates. Plasmonics, p. 1 (2018)

32. Alam, T.M., Pearce, C.J.: Impact of graphene incorporation on the orientational order of graphene/liquid crystal composites. Chem. Phys. Lett. 592, 7 (2014)
33. Al-Zangana, S., Iliut, M., Turner, M., Vijayaraghavan, A., Dierking, I.: Properties of a thermotropic nematic liquid crystal doped with graphene oxide. Adv. Opt. Mater. 4, 1541 (2016)

34. Javadian, S., Dalir, N., Kakemam, J.: Non-covalent intermolecular interactions of colloidal nematic liquid crystals doped with graphene oxide. Liq. Cryst. 44, 1341 (2017)

35. Marinova, V., Tong, Z.F., Petrov, S., Karashanova, D., Lin, Y.H., Lin, S.H., Hsu, K.Y.: Graphene oxide doped PDLC films for all optically controlled light valve structures. In: Optics and Photonics for Information Processing X, vol. 9970, p. 997009 (2016)

36. Hourri, A., Jamée, P., Bose, T., Thoen, J.: Broadband dielectric relaxation study of $6 \mathrm{CB}$ and $6 \mathrm{CB}$-aerosil dispersions in the nematic and isotropic phases. Liq. Cryst. 29, 459 (2002)

Publisher's Note Springer Nature remains neutral with regard to jurisdictional claims in published maps and institutional affiliations. 